\section{Questions about AIDS}

SIR - A growing wave of popular press attention is currently being focused on P. H. Duesberg and the contention that the human immunodeficiency virus (HIV) does not cause AIDS. Two years ago, Duesberg listed 11 phenomena that he considered to be paradoxical in the context of the hypothesis that HIV causes $\mathrm{AIDS}^{1}$. I responded by showing how these paradoxes can be resolved in the context of an autoimmunity model of immunopathogenesis ${ }^{2}$. Duesberg has not responded to these resolutions of his paradoxes. The set of paradoxes is potentially useful. The ability to resolve them is a convenient benchmark for the evaluation of competing theories of AIDS pathogenesis, and may bring focus to an otherwise rather undisciplined debate. I challenge proponents of other pathogenesis models to show that their models can match the performance of our autoimmunity model in resolving the Duesberg paradoxes.

\section{Geoffrey $\mathbf{W}$. Hoffmann}

Departments of Physics and Microbiology, University of British Columbia,

Vancouver, BC, Canada, V6T $1 Z 1$

1. Duesberg, P. H., Res. Immunol. 141, 5-11 (1990).

2. Hoffmann, G. W. Res. Immunol. 141, 701-709 (1990)

SIR - Perhaps others in my position have thought about this question and would also welcome an answer. I receive a reasonably large number of reprints from areas of the world where AIDS is rampant, and would like some assurance that if one gets a paper-cut finger from the saliva-licked sealed envelope, one needn't worry about the possibility of viable AIDS virus passage. Is there some assurance/information knowledgeable readers can provide?

Lee Frank

Pulmonary Research Division,

University of Miami School of Medicine, PO Box 016960 .

Miami, Florida 33101, USA

SIR - At the alternative AIDS conference in Amsterdam in May, I proposed that American/European AIDS diseases, above their normal background, are caused by recreational drugs and the antiviral drug AZT. In a News and Views article (Nature 357, 188; 1992), you blame me for "failure ... to respond to the counterarguments", reliance on "circumstantial" evidence, and for "enjoying [myself] so hugely at the expense of lesser mortals who have managed so grossly to misunderstand AIDS

Unfortunately Nature fails to understand how difficult it is to present in one talk sufficient evidence to counter all claims of the virus-AIDS hypothesis that

\section{Peter Duesberg}

have been publicized in more than 60,000 papers and how extremely difficult it is to publish the basis of my drug-AIDS hypothesis in the Proceedings of the National Academy of Sciences (USA). My paper was rejected even though I belong to the academy and membership typically includes the privilege of publishing without editorial review.

I decided to soften my "punches" against the virus-AIDS hypothesis with humour. This is not to say that I enjoyed myself at the expense of lesser mortals. Indeed, the proponents of the virusAIDS hypothesis are by no means "lesser". Instead, I am advancing my hypothesis very much at my own expense. Since I challenged the virusAIDS hypothesis, which is entirely unproductive in terms of public health benefits, I have been excommunicated by the retrovirus-AIDS community with noninvitations to meetings, noncitations in the literature and nonrenewals of my research grants, which is the highest price an experimental scientist can pay for his convictions

Department of Molecular

and Cell Biology,

University of California,

Berkeley, California 94720, USA

\section{Why cheat?}

SIR - The present debate over fraud and unethical behaviour in science $(\mathrm{Na}$ ture 356, 730; 1992) fails to ask why people cheat. Until this question is asked and answered, and the incentives for cheating are removed, some people will continue to do so, regardless of the rules and guidelines.

People cheat only if their expectation of gain exceeds their fear of exposure. Cheating does not advance science, so its presence indicates that something is wrong with the reward system. People are rewarded (by jobs or grants) for filling their curricula vitae with unexamined papers. This reward system is also responsible for such phenomena as the 'minimum publishable unit' and competitive 'grantsmanship', by which the efforts of honest scientists are diverted from productive research.

The present funding system in science (at least in the United States) is destructive because it has replaced healthy competition (to make discoveries or to develop useful products) with wasteful competition (to have the longest $c . v$. or highest ranked funding proposal). Cheating is rarely caught, and is rewarded in this wasteful competition. The solution must restructure the evaluation process so that it is based on a proposer's entire record of accomplishment rather than on the promises made in a proposal. Reform should also guarantee a minimal level of support to every productive and original scientist, drawing the required resources from larger groups organized around a successful grant-getter. Such a concentration of people and resources into large groups chokes original and venturesome research because only the group leader is independent, and even he is constrained by the need to market his funding proposals to his peers and the pressure to find support for his group.

Competitive review of proposed research ensure that only consensus science will be supported. New and original ideas are unlikely to attract consensus approval, and are discouraged by the present system. Most scientists therefore disguise their intent in the proposals, which encourages more serious cheating.

\section{Jonathan Katz}

Washington University,

Campus Box 1105 ,

One Brookings Drive,

St Louis, Missouri 63130-4899, USA

\section{Human insulin}

SIR - In his interesting Commentary (Nature 356, 375; 1992), Simon Wolff says that there is no controversy over human insulin in the United States. This is not the case; we are aware of several diabetic patients in the United States who are unhappy with human insulin, and there are legal cases in process now where doctors are being sued for continuing to prescribe it. There are diabetic patients in other countries who have had problems with human insulin, but where the authorities do not admit there is a problem. These include France and notably Australia, where all other forms of insulin have been withdrawn. It is our view that the only reason there are no acknowledged prob!ems with human insulin in these countries is that they do not have a method of collecting the information or that patients are not being listened to.

Wolff does not mention that a number of diabetic patients have been changed back from human insulin to porcine insulin, and that these patients find that their symptoms of hypoglycaemia have returned. No account has been taken of this fact by anybody, and until someone is able to collate this information it may be that we are still sitting on a human insulin timebomb.

M. R. Kiln

$12 \mathrm{Elm}$ Road, Beckenham, Kent, UK Amanda Sugarman

12 Primley Park Walk, Leeds, UK 